\title{
OLHANDO POR DENTRO: INOVANDO E AMPLIANDO O ENSINO DE CIÊNCIAS COM A TECNOLOGIA DO CROMA KEY PARA PRODUÇÃO DE VÍDEO-AULAS.
}

\author{
SALVADOR/BA JUNHO/2018
}

\author{
Graça Regina Armond Matias Ferreira - UFBA/CEMITEC - ginamatias@hotmail.com \\ Sandra Lucia Pita de Oliveira Pereira - UFBA/CEMITEC - sandrapita@uol.com
}

Tipo: Relato de Experiência Inovadora (EI)

Categoria: Métodos e Tecnologias

Setor Educacional: EDUCAÇÃO INFANTIL E FUNDAMENTAL, EDUCAÇÃO MÉDIA E TECNOLÓGICA, EDUCAÇÃO CONTINUADA EM GERAL

\begin{abstract}
RESUMO
Este artigo tem como objetivo apresentar a possibilidade do uso pedagógico da tecnologia 'Croma Key', como estratégia de aprendizagem no ensino de ciências naturais, tanto na modalidade presencial (ou semipresencial), como na educação a distância. A metodologia utilizada neste trabalho foi a de planejamento, execução, gravação e aplicação dos vídeos didáticos produzidos, utilizando essa tecnologia, nas aulas de Ciências e Biologia da Rede Básica de Ensino na Bahia, nos estúdios do EMITEC/BA, entre os anos de 2015 e 2007. Ao todo foram 10 vídeos autorais produzidos com temáticas variadas, entre Fisiologia Humana, Botânica e estudo dos Reino Animal - Vertebrados. Os vídeos produzidos têm sido utilizados como recurso pedagógico nas aulas de Ciências, na rede Municipal de Ensino e em Biologia, nas aulas do EMITEC/BA. Os resultados, além de originar produções midiáticas autoral, foi a receptividade do público, que relatou ter compreendido melhor os conteúdos trabalhados após experimentar essa tecnologia; o reconhecimento e a linguagem apropriada também auxiliam na compreensão do conteúdo, a escolha do uso das imagens e cenário também trouxe pontos positivos, pois ao mesmo tempo que se explica o conteúdo, este podem ser visualizados através de imagens, esquemas e/ou desenhos, permitindo explorar vários campos de aprendizagem.
\end{abstract}

Palavras-chave: croma key; ensino de ciências; produção de vídeos; tecnologia digital; educação a distância; cultura digital

\section{AGRADECIMENTOS}

AGRADECEMOS A EQUIPE PEDAGÓGICA DAS INSTITUIÇÕES POR POSSIBILITAR A UTILIZAÇÃO DESSE RECURSO NAS AULAS. A EQUIPE DE EDIÇÃO E FILMAGEM DO EMITEC PELA PACIÊNCIA E AUXILIO NA GRAVAÇÃO DAS VÍDEO-AULAS. 


\section{INTRODUÇÃO}

A popularização da Internet iniciada no final dos anos 1990 possibilitou uma nova forma de ensino e aprendizagem, fazendo uso dos recursos tecnológicos, uma vez que o avanço proporcionado pelas Tecnologias de Informação e Comunicação (TIC), assim como a expansão da Internet romperam as barreiras de acesso à educação formal e nãoformal (MOORE, KEARSLEY, 2008; MORAN, 2000). Esses fenômenos serviram de mola propulsora para o aprimoramento das técnicas pedagógicas pelos docentes, visto que os educandos em constante contato com as tecnologias no seu cotidiano sentem-se desmotivados com estratégias tradicionais abordadas em sala de aula, muitas vezes, não encontrando significado para sua vida com o que aprende na escola.

Nesse sentido, para que o processo de ensino e aprendizagem tenha efetividade tornase necessário a ocorrência de uma aprendizagem significativa para o aluno, fazendo uso de recursos que tenham uma linguagem atrativa e instigante. É importante que os materiais disponibilizados sejam preparados e contextualizados com o ambiente em que se inserem. A seleção desses recursos deve ser pensada em consonância com o tema que será abordado para que haja uma compatibilidade entre eles e facilite a aprendizagem. Desta forma, deve-se levar em consideração que o mais relevante é a qualidade da mensagem e não o meio utilizado para enviá-la, mas se o meio não for adequado, a qualidade da mensagem também pode ser comprometida e, consequentemente, todo o processo (MOORE, 2008).

\section{OBJETIVO}

O objetivo principal deste trabalho é disseminar a prática de produção e gravação de vídeo-aulas utilizando o recurso "Chroma Key", bem como sua inserção como objeto de aprendizagem dinamizador durante as aulas regulares do Ensino Médio com Intermediação Tecnológica (EMITEC/BA), entre 2015 e 2017. A vídeo-aulas também foram aplicadas como forma de validação e identificação de melhorias, nas aulas de Ciências da Rede Municipal de Ensino, em 2017 e 2018.

\section{REFERENCIAL TEÓRICO}

As aulas de ciências da natureza devem levar ao aluno à investigação científica, 
fazendo com que ele tente responder às perguntas, fornecendo o mínimo necessário para que ele desenvolva o raciocínio e traga a resposta. O que ocorre é as atividades escolares, na maioria das vezes, acontece dissociado do cotidiano do aluno e se apresenta ineficiente no objetivo de promover uma educação científica. A experiência docente tem mostrado que apesar dos constantes avanços da ciência e das tecnologias educacionais observa-se que o ensino de Biologia e Ciências permanecem ainda, na maioria dos casos, restrito às aulas expositivas com mínima participação dos alunos.

Quando se trata de envolver novos processos de ensino-aprendizagem no campo da educação, é preciso estar atendo as demandas da "juventude", para oportunizar essas estratégias como mecanismos de aprendizagem. Tal como defende Belloni "a questão da integração das TIC aos processos educacionais transcende as questões puramente técnicas para se situar no nível da definição das grandes finalidades sociais da educação" (BELLONI, 2001, p. 29).

Todas essas pressões forçam as escolas a repensar seus métodos, em resposta às exigências de um novo tempo. Assim, um dos grandes desafios para as instituições escolares neste século é, não se curvando de forma submissa às necessidades de produção ou às determinações do mercado de trabalho, reafirmar seu compromisso institucional com um ensino que permita um vínculo crítico quanto às novas formas de relação social, nas quais as tecnologias ocupam destacado papel. Além de não apenas privilegiar o domínio das técnicas necessárias para o uso das máquinas, promover ações que visem estabelecer conexões dialógicas entre todos os sujeitos que convivem no espaço escolar, em uma perspectiva de educação para a cidadania plena, "resgatando os ideais de democratização do conhecimento e da informação como instrumentos de emancipação" (MORAES, 2005, p.297)

Este exercício faz do professor um mediador do conhecimento, atraindo mais as aulas de ciências para a investigação, passando pelos passos do método científico até encontrar uma resposta ao seu questionamento. É dessa maneira que os conteúdos deveriam ser ensinados, e que a equipe pedagógica do EMITEC se baseia, justificado com o conceito de "pedagogia da pergunta" de Paulo Freire, 1985: (...) todo conhecimento começa pela pergunta e pela curiosidade, que é uma pergunta. É na pergunta que está o interesse, ou a fome pelo conhecimento necessário para nutrir o pensamento na busca de significados (Freire, 1985, p. 07).

Compartilhamos esse pressuposto, de que a educação seja ela em qualquer modalidade de ensino, não pode acontecer sem esse princípio. A pergunta desperta e conserva a curiosidade e a crítica e, nesse percurso, acaba melhorando consideravelmente a 
maneira de pensar, imaginar e criar como resultado do exercício de diferentes habilidades e competências.

É com base neste princípio norteador, que as aulas de biologia traçam as suas estratégias pedagógicas, utilizando de sequencias didáticas que induzem o aluno a refletir sobre o seu espaço, buscando uma autonomia reflexiva e produção de atividades que valorizem não somente o conhecimento do conteúdo trabalhado, mas valorizando o espaço e envolvendo a criação bem como a ludicidade na construção da aprendizagem.

Uma das estratégias utilizadas para buscar essa dinamização é a utilização de vídeoaulas produzidas através do Chroma Key. Trata-se de uma técnica de efeito visual que consiste em colocar uma imagem sobre uma outra através do anulamento de uma cor padrão, como por exemplo o verde ou o azul. Consiste em uma técnica de processamento de imagens cujo objetivo é eliminar o fundo de uma imagem para isolar os personagens ou objetos de interesse que posteriormente são combinados com outra imagem de fundo.

\section{PROCEDIMENTOS METODOLOGICOS}

A metodologia utilizada para realização deste trabalho foi a pesquisa de campo e bibliográfica, tendo como aporte teórico Burns et al. (2003), Korbes e Invernizzi (2010), entre outros, para planejamento dos vídeos, consultando literaturas atualizadas sobre 0 tema. A gravação e edição foi feita pela equipe técnica dos estúdios do EMITEC/BA, através de indicações relacionadas ao tópico e planejamento feito por meio de roteiro pré-definido. Após a edição o vídeo foi validado, e utilizado como recurso pedagógico nas aulas de Biologia e Ciências. Após a aplicação dos vídeos, foram feitas atividades relacionadas ao conteúdo do vídeo, como como a percepção dos mesmos como contribuição na aprendizagem, permitindo coletar diversas narrativas sobre todo 0 processo.

\section{APRESENTAÇÃO E DISCUSSÃO DOS RESULTADOS}

Os resultados obtidos, além dos roteiros que podem ser continuamente melhorados, foi o produto originado com o uso dessa tecnologia digital, muito utilizada na área jornalística, agora como ferramenta educativa de aprendizagem. As vídeo-aulas 
produzidas (FIGURA 01), de cunho autoral, tornou-se uma ferramenta pedagógica muito eficiente como apoio ao ensino de ciências, permitindo visualizar de uma maneira diferenciada os conteúdos a serem trabalhados.

FIGURA 1. Imagens de algumas das vídeo-aulas planejadas e produzidas utilizando o Croma Key (Arquivo pessoal, 2017)

Em relação aos resultados sobre as narrativas produzidas pelos alunos que assistiram as vídeo-aulas, foi muito importante, visto que se trata de um programa que envolve o uso das tecnologias em sala de aula, os alunos se sentiram motivados, ficaram atentos a explicação e tiraram dúvidas sobre o assunto abordado. A maior parte das percepções foram de elogios e curiosidades sobre a tecnologia. Ao realizar os exercícios, percebeu que todos os alunos acetaram as questões, que trazia como elementos, os itens que foram citados no vídeo e discutidos durante as aulas, permitindo uma avaliação positiva do uso desse recurso como finalidade pedagógica.

\section{CONSIDERAÇÕES FINAIS}

Diante dos resultados apresentados, em turmas do ensino médio com intermediação tecnológica, e alunos do ensino de ciências, demonstra-se que uma solução possível para despertar o interesse dos alunos, está na inovação e diversificação das práticas escolares. Estas deixariam de ser centradas em ações rotineiras e conteudistas, e utilizariam estratégias motivadoras e lúdicas que valorizem o saber científico, convidando o estudante a buscar mais informações além daquelas apresentadas em sala de aula.

Sendo assim, os relatos aqui apresentados são relevantes como mecanismo de promoção do conhecimento, como também de desenvolver práticas para educação na área de Ciências Naturais e suas Tecnologias. Sabendo-se da importância da aprendizagem significativa para a educação básica, percebe-se a relevância do trabalho descrito, não apenas como estratégia de diversificação das aulas, mas como uma ferramenta de educação para, atingindo os alunos, levando-o a atuar como agente multiplicador dessa ação dentro da sua comunidade, propiciando um aprendizado 
significativo com uso de tecnologias digitais, revelando mais uma ação eficaz para a garantia do exercício pleno para a efetiva cidadania.

\section{REFERÊNCIAS}

BELLONI, Maria Luiza. O que é mídia-educação. Campinas: Autores Associados. Polemicas do Nosso Tempo, 2001.

BURNS, Terri; O'CONNOR, John; STOCKLMAYER, Susan. Science communication: a contemporary definition. Public Understanding of Science, v. 12, n. 2, 2003.

FREIRE, PAULO. Pedagogia da Liberdade. São Paulo: paz e Terra. 1985.

KORBES, Clecí e INVERNIZZI, Noela. Educação não-formal sobre reprodução assistida: divulgação científica na Folha de S.Paulo. Trab. educ. saúde (Online) [online]. 2010.

MOORE, Michel; KEARSLEY, Greg. Educação a distância: uma visão integrada. São Paulo: Cengage Learning, 2008.

MORAN, José Manuel; MASETTO, Marcos; BEHRENS, Marilda. Novas Tecnologias e Mediação Pedagógica. São Paulo: Papirus, 2000.

MORAES, Carlos Vinicius de Oliveira. De um mundo para a escola, da escola para o mundo: reflexão sobre meio e sobre fins. Revista comunicação \& educação. Ano X, número 3. Set/dez 2005. 